\title{
Assessment of the Quality of Urban Transport Services in Nigeria
}

\author{
Adetunji Musilimu Adeyinka. (Ph. D) \\ Department of Geography, Faculty of Atts \& Social Sciences \\ Federal University Lokoja, Kogi State, Nigeria \\ Phone+2348066245425Email:maadetunji@yahoo.com
}

Doi:10.5901/ajis/2013.v2n1p49

Abstract

Transport services are inadequate in quality and qualitative terms in most developing countries such as Nigeria which, relies on the importation of fairly used vehicles to meet the travel demands. The poor service delivery of transport system had created impediment towards the smooth movement of people, goods and services in some of urban centres in Nigeria. This study is designed to investigate the quality of transport services in Ibadan metropolis. The study area covered the eleven local government areas that make up Ibadan metropolis. Stratified sampling technique was used to select two political wards from each of the local government areas identified in the city. The twenty two political wards sampled were re-grouped into three geographical areas based on land use characteristics and population density. These are high, medium and low density. In each of the three geographical areas identified in the city, a systematic random sampling procedure was employed to select one in every twenty buildings along the major streets. In each of the buildings sampled, only one household is randomly selected for interview. An average of one hundred copies of the questionnaire was administered in each of the density area. Descriptive and inferential statistics were used to analyze the data. The findings revealed that some of the urban residents who are less accessible to transport services in their neighborhood commute on foot to meet their travel demands. Many of the urban residents expressed their dissatisfaction with the transport services available in the city. Further analysis showed that household's income is highly correlated with modal choice in the city. The result of the analysis further revealed that some of the intra-transport services are poorly maintained. The study concluded that there is need to revitalize the transport services in urban centres in Nigeria so as to improve the accessibility characteristics of urban residents and promote sustainable transport development.

Key Word: Urban, Households, Transport Services, And Plannig.

\section{Introduction}

Urban transport services in Nigeria is inadequate both in quality and quantitative terms considering the rate of population growth and the economic condition of an average Nigerian on the affordability of transport services to meet his or her travel demands over the past four decades. The structural adjustment programme of the middle 80 's had made the importation of new automobile vehicles relatively expensive to purchase for urban mobility in the country. Similarly, the price of motor spare parts had risen astronomically and many Nigerians could hardly maintain their old vehicles which invariably compounded the mobility crises in Nigerian towns and cities. Incidentally most of urban trips in Nigeria are made by road, rail and water based mode and these accounted for about $95 \%$, and the remaining 5\% were mainly by walking (Oyesiku ,200I).

It is pertinent to note that of all the trips made by vehicles, $70 \%$ were by public transport, which is dominated by private sector operators. According to Oyesiku (2002), more than $95 \%$ of all urban public transport journeys in Nigeria were provided by private operators using mainly taxis and 
paratransit buses. It is interesting to note that many of the urban residents are less accessible to these transport services. Besides, the service delivery of public transport operators is less satisfactory to the urban commuters in Nigeria. Most of the research works carried out on the mode of operation of public transport services in Nigeria do not consider the quality of transport services in relation to comfort, affordability, safety and income level, which are all of paramount importance to mobility pattern of urban residents in any country of the world. The focus of this research therefore is to assess the quality of transport services in Ibadan metropolis with the view to improving the mobility characteristics of urban residents and promoting sustainable transport development in the study areas and many other cities in Nigeria.

\section{Theoretical Frame Work and Review of Literature}

Modal choice represents an important household's travel characteristics in transportation research. There are many theories available in the literature to explain transportation planning. These include travel demand model, gravity model, residential location model, traffic assignment model and modal split model. The theory that we consider very appropriate to explain transport services in this context is the modal split model. According to the model, different modes of urban transport are available to urban commuters; these include cars, buses, walking, motorcycles, taxis, ships or trains. The choice of a particular mode would depend on such factors as the trip type, trip purpose, the level of satisfaction of transport services, transport fare / cost associated with the available modes, comfort and income of the commuters (Adetunji, 2010; Ogunsanya, 1986; Okonko, 2000).

In a study of urban mobility patterns in Ilesa in South western Nigeria, Adetunji (2010) reported that the household's income affects the modal choice of urban resident. According to him, high income earners travel by their personal cars to different activity patterns while the low income earners commute by foot for short distances and rely on public transport services for which exorbitant fares are charged. This is contrary to what exists in some other countries of the world, particularly in China where the train is the principal mode of transport for all categories of trips by urban residents while the local trips are made by public transport services (buses and taxis) which are cleaner and more comfortable. The buses are extremely cheap and commuters pay the same amount of transport fare irrespective of the distance travel (http://www.chinese-culture.net/html/china_public_transport.html, 20I2)

In a study of public transport in Nigeria, the World Bank (1990) and Adeniji (2000) reported that taxis (and private vehicles carrying fare paying passengers) represent about $53 \%$ of the public transport trips, while 30\% made use of motorcycles. In many cities in developing countries, motorcycles account for about $90 \%$ of feeder trips to taxi and minibus terminal.

Similarly, in a study of the supply of transport infrastructure in Lagos metropolis, Ogunsanya (2004) found that most urban road networks are not only poorly developed with feeder street grossly inadequate, but also these inadequacies more often than not forced vehicles to concentrate on the primary roads with serious implications on commuters modern choice and mobility patterns especially along the same urban transport corridor.

World Bank 1993; World Bank 1997 and Adesanya et al 2002 affirmed that urban poor in Nigeria pay a very high proportion of their income for transport services and spent long periods of time travelling and waiting for infrequent and unreliable bus services. They also reported that due to inadequate access to infrastructure and services, the urban poor also have limited access to educational institutions and social services. However, many of the works done on the public transport in Nigeria do not have critical assessments of the quality of the service delivery of transport operators in some of the cities studied. It is on this premise that this study is designed to examine the quality of transport services 
in Ibadan metropolis in Nigeria with a view to improving and sustaining transport infrastructure in Urban centres in Nigeria and similar other cities in Africa.

\section{The Study area}

Ibadan is a typical city in Nigeria which has experienced high rate of urbanization over the past four decades. The study area comprises eleven contiguous local government areas. These are Ibadan North, Ibadan North West, Ibadan South West, Ibadan South East, Ibadan North East, Egbeda, Akinyele, Moniya, Ona ara, and few others. The traditional occupation of Ibadan people are farming and trading in varieties of goods. The favourable climatic conditions and good soil types have encouraged the production of both food and cash crops in Ibadan region. The major food crops grown include yam, cassava, maize, tomatoes and many others. Similarly, the cash crops cultivated include cocoa, palm oil, and little coffee. The abundant food supply and peacefully co-existence in the city had encouraged many people to settle in Ibadan to earn their livelihood.

Like many other urban centres in Nigeria, Ibadan grew organically without any form of master planning (Ipingbemi, 2009). The high density area is mainly occupied by the indigenous Ibadan people. These areas include Mapo, Atipe, Labiran, Bere and Oja Oba. Many of the intra-city roads in this area are too narrow to accommodate vehicular traffic which invariably makes mobility temporarily difficult during the rainy season. The situation at low density areas of the city is different from the high density areas because the areas are well planned and occupied mostly by the high income earners and top civil servants. Some of the roads in this part of the city are well tarred with bitumen and are motorable in most parts of the year.

The land use arrangement in Ibadan metropolis is greatly affected by movement patterns of urban residents in the city. For instance, many of the employment generating organizations i.e Government Secretariats, public land uses such as schools, hospitals and commercial centres like Gbagi, Dugbe, Sasa and Ogunpa markets generate more trips than areas of the city that are mainly for residential purpose. The daily commuting to different activity centres in this traditional city requires more automobiles thus culminating in more complex traffic problems such as noise pollution and emission of toxic substances that are inimical to human health in the urban environment. It is interesting to note that transport infrastructure in Nigeria are poorly developed. Many of the intra city routes in Ibadan are poorly designed and rarely maintained, this compounds the mobility crises in the city.

Different modes of transport services are available in the city to enhance the movement patterns of urban residents. These include motorcycles, taxis/ cabs and paratransit modes. However, taxis and buses operate on the major roads while tricycles and motorcycles ply different categories of roads in the city. The stringent policy imposed on the importation of new vehicles and high costs of spare parts have made it difficult to have better transport services for urban commuters. However, many of the city inhabitants are generally low income earners who cannot afford to buy new automobiles to enhance their daily commuting. The resultant effect of this is that many of the urban residents in the city depend on poorly maintained public transport services to meet their day to day transactions. It is on this background that this study assesses the quality of transport services in Ibadan one the very large cities in Nigeria. 


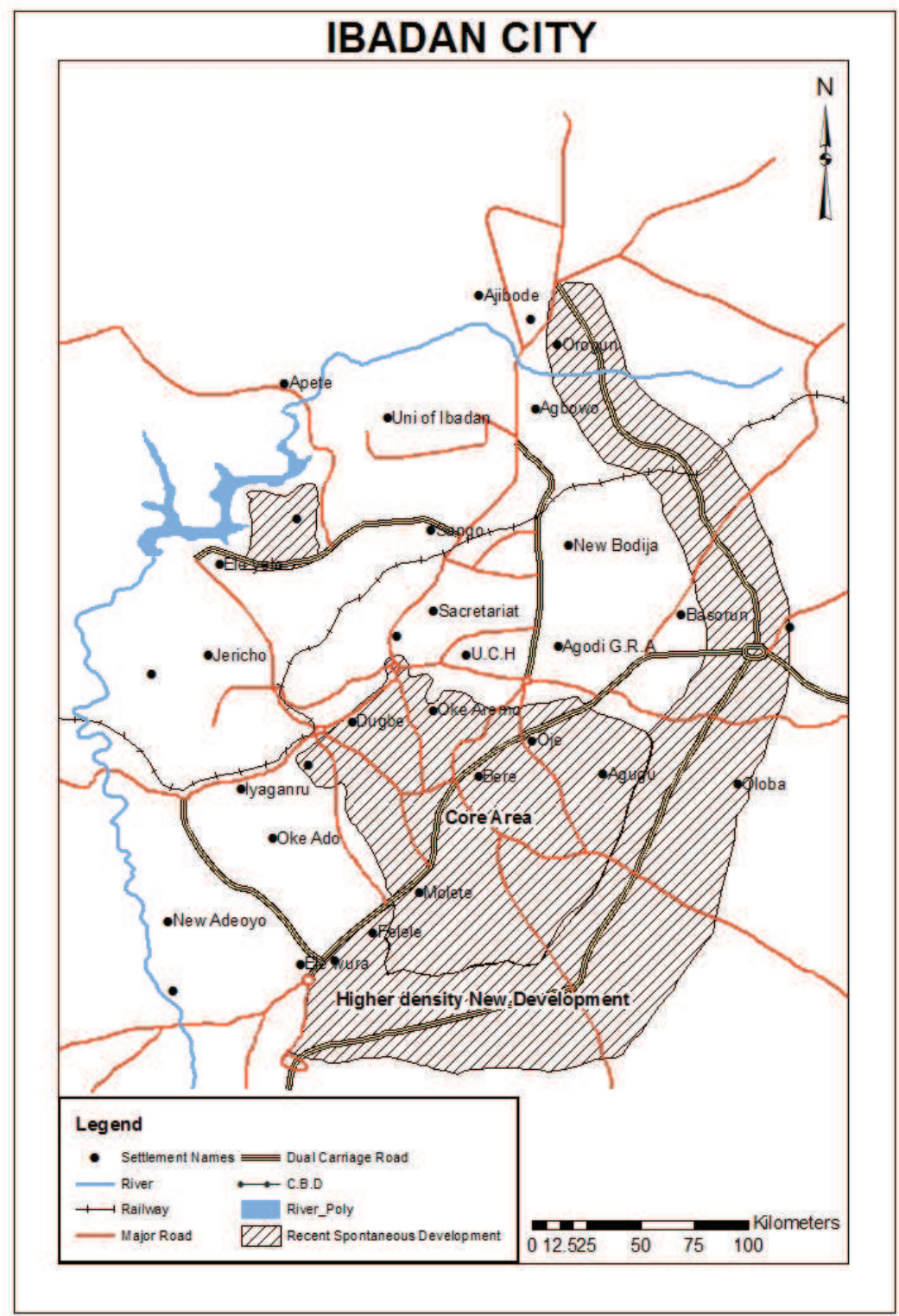

\section{Methodology and Materials Used for the Research.}

The study area covers the eleven local governments' areas that make up Ibadan metropolis. A stratified sampling technique was used to select two political wards from each of the local government areas identified in the city. These twenty two political wards sampled were re-grouped into three geographical areas based on land use characteristics and population density. These are high, medium and low density. 
In each of the three geographical area identified in the city, a systematic random sampling procedure was employed to select one in every twenty buildings along the major street. In each of the buildings sampled, only one household is randomly selected for interview. An average of one hundred copies of the questionnaires was administered in each of the density areas. Descriptive and inferential statistics were used to analyze the data.

\section{Results and Discussion of Findings}

The findings revealed that different modes of transport are available to urban commuters in Ibadan metropolis. These include trekking, tricycles, motorcycles, cabs/ taxi, buses and cars. Table I reveals that $21 \%$ of the urban residents who are less accessible to motorized modes of transport in their neighborhoods indicated that they patronize motorcycles more frequently for their day to day transactions. 32.7\% claimed that they travel mostly by their personal cars. An approximately $29.3 \%$ and I7\% of the sampled populations depend on paratransit buses and taxis for their intra city movement. This is an indication of inadequate public transport services in Ibadan metropolis and similar other cities in Nigeria. However, in some of the advanced countries, buses of different categories are designed to convey large number of passengers from one place to another.

Table I: Most Accessible Mode of Transport

\begin{tabular}{|ll|c|c|c|c|}
\hline & & Frequency & Percent & Valid Percent & Cumulative Percent \\
\hline Valid & Motorcycle & 63 & 21.0 & 21.0 & 21.0 \\
& Car & 98 & 32.7 & 32.7 & 53.7 \\
Bus & 88 & 29.3 & 29.3 & 83.0 \\
cab/taxi & $5 \mathrm{I}$ & 17.0 & 17.0 & 100.0 \\
Total & 300 & I00.0 & I00.0 & \\
\hline
\end{tabular}

Source: Author's Computation, 2012

The income of the commuters determines the modal choice in the city. For instance, table 2 revealed that $54.5 \%$ of high income earners who own personal means of transport indicated that they travel by their cars. 18.2\% depend on each of motorcycle and taxi. Further analysis indicates that $68.2 \%$ of the urban poor rely on the public transport (motorcycle $=25.6 \%$, buses $23.1 \%$ and taxis $17.6 \%$ ). An approximately $27.2 \%$ of low income earner claimed that they rely on car pool for their intra- city movement.

Table 2: Household Modal Choice among Different Income Earners in the Study Area.

\begin{tabular}{|l|c|c|c|c|c|c|}
\hline Income & Trekking & Tricycle & Motorcycle & Car & Bus & Taxi/ Cab \\
\hline Low & $5.1 \%$ & $1.0 \%$ & $25.6 \%$ & $27.2 \%$ & $23.1 \%$ & $\mathrm{I} \% .9 \%$ \\
\hline Medium & $4.8 \%$ & $8.4 \%$ & $19.3 \%$ & $43.4 \%$ & $7.2 \%$ & $16.9 \%$ \\
\hline High & $0.0 \%$ & $9.1 \%$ & $18.2 \%$ & $54.5 \%$ & $0.0 \%$ & $18.2 \%$ \\
\hline $\begin{array}{l}\text { Ground Total in } \\
\text { Percentage }\end{array}$ & $4.7 \%$ & $3.7 \%$ & $23.3 \%$ & $33.3 \%$ & $17.0 \%$ & $17.7 \%$ \\
\hline
\end{tabular}

Source: Author's Computation, 2012 
Further analysis revealed that the age of the respondents, possession of personal means of transport, distance travel, average time taken and modal choice consideration vary significantly across the three density areas identified in the city; Possession of means of transport, $\mathrm{F}=7.005<.00$; Distance travel, $\mathrm{F}=3.2 \mathrm{I} 3<.04 ;$ Time taken, $\mathrm{F}=7.244<.00$ and Modal choice, $\mathrm{F}=3.689<.03$ )

Table 3: Modal choice Across the Density Areas Identified in Ibadan metropolis.

ANOVA

\begin{tabular}{|ll|c|c|c|c|c|}
\hline & & $\begin{array}{c}\text { Sum of } \\
\text { Squares }\end{array}$ & Df & $\begin{array}{c}\text { Mean } \\
\text { Square }\end{array}$ & F & Sig. \\
\hline Possession of personal means & Between Groups & 3.377 & 2 & I.688 & 7.005 & .001 \\
& Within Groups & 71.593 & 297 & .241 & & \\
& Total & 74.970 & 299 & & & \\
Average distance travelled per & Between Groups & 4.043 & 2 & 2.022 & 3.213 & .042 \\
day & Within Groups & 186.873 & 297 & .629 & & \\
& Total & 190.917 & 299 & & & \\
Mode of transport embark & Between Groups & 12.149 & 2 & 6.075 & 3.689 & .026 \\
upon mostly & Within Groups & 489.087 & 297 & 1.647 & & \\
Total & 501.237 & 299 & & & \\
Household Income per & Between Groups & 1.713 & 2 & .857 & 2.203 & .112 \\
Month & Within Groups & 115.523 & 297 & .389 & & \\
& Total & 117.237 & 299 & & & \\
Average times taken for trips & Between Groups & 7.804 & 2 & 3.902 & 7.244 & .001 \\
& Within Groups & 159.966 & 297 & .539 & & \\
& Total & 167.770 & 299 & & & \\
Mode of transport preferred & Between Groups & .294 & 2 & .147 & .193 & .825 \\
& Within Groups & 226.852 & 297 & .764 & & \\
in terms of safety & Total & 227.147 & 299 & & & \\
\hline
\end{tabular}

Source: Author's Computation, 2012

Table 4 revealed that the distance travel in Ibadan metropolis has a low positive correlation between the average times taken to reach activity travel patterns in the city. The correlation coefficient is $\mathrm{r}=0.47$ and it is significant at $0.01 \%$. 
Table 4: Relationship between distances travelled and average time taken to reach activity travel patterns in Ibadan.

\section{Correlations}

\begin{tabular}{|ll|c|c|}
\hline & & $\begin{array}{c}\text { Average times taken } \\
\text { for such trip }\end{array}$ & $\begin{array}{c}\text { Average distance } \\
\text { travel per day }\end{array}$ \\
\hline Average times taken for such trip & Pearson Correlation & $\mathrm{I}$ & $\left..4655^{(\ldots+}\right)$ \\
& Sig. (2-tailed) & & .000 \\
& $\mathrm{~N}$ & 300 & 300 \\
Average distance travelled per day & Pearson Correlation & $.465(2-)$ & $\mathrm{I}$ \\
& Sig. (2-tailed) & .000 & 300 \\
& $\mathrm{~N}$ & 300 & 300 \\
\hline
\end{tabular}

Correlation is significant at the O.OI level (2-tailed).

Source: Author's Computation, 2012

There is no route schedule for public transport services in urban centres in Nigeria. On several occasions, public transport operators pick up their passengers along the road sides and alight at will without consideration for other road users and time constraints of their passengers. Table 5 indicates that $62.3 \%$ of the commuters indicated that they experienced stop over during their trips. The remaining $37.7 \%$ claimed that they do not experience stop over either when loading or off loading passengers.

Table 5: Experience of stop overs on your trips

\begin{tabular}{|ll|c|c|c|c|}
\hline & & Frequency & Percent & Valid Percent & $\begin{array}{c}\text { Cumulative } \\
\text { Percent }\end{array}$ \\
\hline Valid & Yes & I87 & 62.3 & 62.3 & 62.3 \\
& No & II3 & 37.7 & 37.7 & 100.0 \\
& Total & 300 & 100.0 & 100.0 & \\
\hline
\end{tabular}

Source: Author's Computation, 2012

The general assessment of the quality of transport services by the urban residents in the study area shows that many of the commuters are not comfortable with the service delivery. Table 6 shows that $42 \%$ of the commuters expressed their dissatisfaction about the maintenance culture of public transport services in the city. While the remaining $58 \%$ of the commuters claimed that they are satisfied with transport services, they see the probable inadequacies in their services as a reflection of the global economic recession which affects every aspect of the economy.

Table 6: The maintenance of Public transport services in Ibadan

\begin{tabular}{|ll|c|c|c|c|}
\hline & & Frequency & Percent & Valid Percent & $\begin{array}{c}\text { Cumulative } \\
\text { Percent }\end{array}$ \\
\hline Valid & Yes & I74 & 58.0 & 58.0 & 58.0 \\
& No & I26 & 42.0 & 42.0 & 100.0 \\
& Total & 300 & 100.0 & 100.0 & \\
\hline
\end{tabular}

Source: Author's Computation, 2012 
It is highly disheartening that many of the public transport vehicles in Ibadan and similar other cities in Nigeria do not have rear lights, brake, spare tyre and good furniture to mention just a few. Table 7 indicates that $45 \%$ of public transport services have good seat cover, $40.3 \%$ have fairly covered seat cover. $14.7 \%$ of the respondents interacted with indicated that the seat covers of the public transport vehicles are bad.

Table 7: Physical appearance of public transport services in the study area.

\begin{tabular}{|ll|c|c|c|c|}
\hline & Frequency & Percent & Valid Percent & $\begin{array}{c}\text { Cumulative } \\
\text { Percent }\end{array}$ \\
\hline Valid & Good & I35 & 45.0 & 45.0 & 45.0 \\
& Fairly good & I2I & 40.3 & 40.3 & 85.3 \\
& Bad & 44 & I4.7 & I4.7 & I00.0 \\
& Total & 300 & I00.0 & I00.0 & \\
\hline
\end{tabular}

Source: Author's Computation, 2012

To worsen the situation, the behavior of the public transport operators to the passengers is a serious concern to the transport planners and many urban stakeholders in Nigeria. It is a usually the practice for public transport operators in Nigeria to assault their passengers irrespective of their status. On many occasions public transport operators have been found fighting with their passengers over insignificant matters which can be settled amicably. Table 8 indicates that $64.7 \%$ of the commuters claimed that they are not satisfied with the behavior of the public transport operators in the city. Only $35.3 \%$ of the respondent claimed that they are comfortable with the behavior of the public transport operators in the city. Many of the commuters struggle to board buses for instance. This is owing to acute shortage of transport services in the city especially early in the morning when commuters are commuting to work places and later in the evening when returning home. Sometimes, it is extremely difficult to differentiate between freight vehicles from passenger vehicles in the city. Many market women carry their luggage on their laps in the vehicle during their intra city movement. It is usual practice to see the passengers carrying their children on their laps in the vehicle because of the shortage of transport services and as a means of reducing the cost of fare.

Table 8: Public transport operator's behavior in the study area

\begin{tabular}{|ll|c|c|c|c|}
\hline & & Frequency & Percent & Valid Percent & $\begin{array}{c}\text { Cumulative } \\
\text { Percent }\end{array}$ \\
\hline Valid & Yes & 106 & 35.3 & 35.3 & 35.3 \\
& No & 194 & 64.7 & 64.7 & 100.0 \\
& Total & 300 & 100.0 & 100.0 & \\
\hline
\end{tabular}

Source: Author's Computation, 2012

In an attempt to minimize the cost of transport fare, many of the urban commuters patronize the cheapest means of transport. Table 9 indicates that $43.7 \%$ of sampled populations claimed that the para transit bus is the cheapest means of transportation they patronize for their day to day transactions in Ibadan metropolis. Another $25.7 \%$ of the respondents who are mostly from the high income group 
$(50 \%)$ claimed that they rely mostly on their personal cars. This category of people has comfortable economic status to maintain their personal vehicles. Further analysis revealed that $24.7 \%$ and $6 \%$ of the commuters rely on taxis and motorcycles respectively for their intra city transport in the study area. When modal choice is disaggregate at different income level, more than $80 \%$ of the urban commuters who patronize motorcycles are from the low income earners.

Table 9: Modal choice preferred in terms of cost (in Percentage \%)

Count

\begin{tabular}{|ll|c|c|c|c|c|}
\hline & \multicolumn{2}{|c|}{ In terms of cost which mode of transport do you prefer } & Total \\
\hline & & Motorcycle & car & Bus & cab/taxi & motorcycle \\
\hline Household & Low Income & $8.2 \%$ & $20 \%$ & $46.7 \%$ & $25.1 \%$ & $100 \%$ \\
Income per & Medium Income & $2.4 \%$ & $32.5 \%$ & $42.2 \%$ & $22.9 \%$ & $100 \%$ \\
Month & High Income & $0.0 \%$ & $50.0 \%$ & $22.7 \%$ & $27.3 \%$ & $100 \%$ \\
Total & & $6.0 \%$ & $25.7 \%$ & $43.7 \%$ & $24.7 \%$ & $100 \%$ \\
\hline
\end{tabular}

Source: Author's Computation, 2012

In the consideration of modal choice by the urban commuters, safety is the most important factor. Table IO shows that the use of personal means of transport particularly cars in Ibadan was ranked highest in term of safety and this accounted for about $48.7 \%$. The use of paratransit buses was ranked second $(25.3 \%)$. This is closely followed by taxi $20.7 \%$. Motorcycle was ranked lowest by the urban commuters.

Table I0: Mode of transport preferred in terms of safety

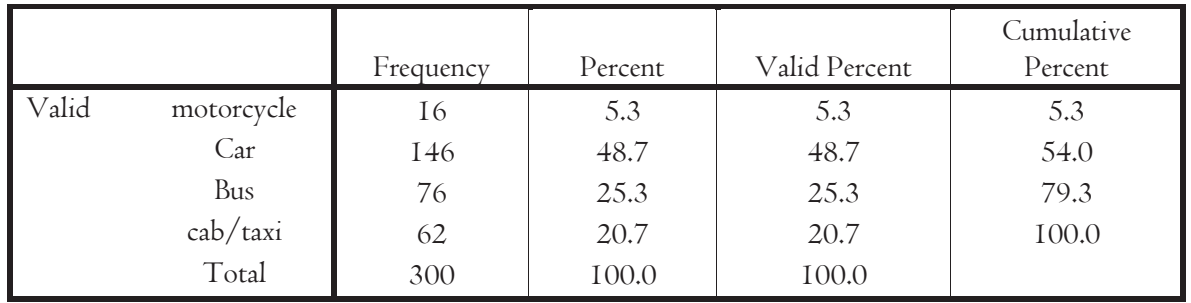

Source: Author's Computation, 2012

\section{Planning Implications}

Access to effective and functioning transport services is one of the key factors for sustainable transport and economic growth in any country of the world. In some of the cities in African countries, transport infrastructure is poorly developed and has adverse effect on the free movement of people and goods. Many of the urban residents spend valuable number of their hours waiting and commuting to different activity patterns on daily basis. The use of mass transits and light rail should be introduced for intra city movements in Ibadan, Lagos, Port Harcourt and many other similar cities in African countries, which has a population of over four millions. 


\section{Conclusions and Recommendation}

The study observed that transport services in Ibadan metropolis are grossly inadequate and poorly maintained. Many urban residents express their dissatisfactions with the services delivery of public transport operators in the city. The use of mass transit should be re- introduced so as to enhance the movement of large number of passengers to their various desired destinations. Also, the governments should participate in the provision of public transport services for the urban commuters at a subsidized rate. Such programmes have been introduced recently by the Ondo State government of Nigeria for both primary and secondary school pupils for their educational trips. Besides, the use of light rail should be encouraged for intra city movement in large metropolitan cities in Nigeria.

\section{References}

Adeniji, .K. (2000): Transport Challenges In Nigeria in the next Two Decades Monograph Ibadan. Nigerian Institute of Social and Economic Research (NISER), Transport Studies Units.

Adesanya, A.; Adeniji, K and Daramola A.Y. (2002): Transport Perspective of poverty in Nigeria A Multidimensional perspective. Edited by Ajakaiye, D.O. and A.S. Olomola, A.S Pp. 235-283.

Adetunji, M. A (2010): Spatial Analysis of Urban Mobility Pattern in Ilesa, Osun State. A PhD thesis submitted to the. Department of Geography of Obafemi Awolowo University, Ile-Ife

Ipingbemi, $O$ (2009): Travel characteristics and mobility constraints of elderly in Ibadan. Journal of Transport Geography. Elsevier. Available online 25 June, 2009.

Olanrewaju, S.A. Fadare, S.O.; Akinlo, A.E and Alawode A.A. (1995): Urban Passenger Transport in Lagos, Nigeria. A Research Monograph. Idrc Urban Transport Project - Department of Economics, Obafemi Awolowo University, Ile-Ife Nigeria Pp.I-55.

Oyesiku, O.K. (200I): City poverty and emerging mobility crisis: The Use of Motorcycle as Public Transport in Nigeria cities. Paper presented at $9^{\text {th }}$ world congress of transport research Seoul, South Korea, $22^{\text {nd }}-27^{\text {th }}$, July.

Ogunsanya, A.A; Vandu-Chikolo I. and Sumaila, A.G. (2004): (eds) Perspectives on Urban Transportation in Nigeria” Nigerian Institute of Transport Technology (NITT), Zarai. M.O.D press, Kaduna PP I-26.

World Bank (1990): Nigeria Urban transports in Crisis, Lagos-West Africa. World Bank Department Infrastructure Division.

World Bank (1993): Poverty Reduction Handbook, World Bank, Washington DC.

World Bank (1997): Taking Action to Reduce Poverty in Sub-Saharan Africa, World Bank, Washington, DC.

(http://www.chinese-culture.net/html/china_public_transport.html) China News Headlines-HOT! I Facts About China Thursday, August 23,2012 